\title{
Intrinsic Viscosity of Polystyrene in Toluene-Supercritical Carbon Dioxide Mixtures
}

\author{
By Masamichi ONISHI, ${ }^{1}$ Yo NAKAMURA, ${ }^{2, *}$ and Takashi NORISUYE ${ }^{1}$
}

Intrinsic viscosities $[\eta]$ were determined for five polystyrene samples ranging in molecular weight $M_{\mathrm{w}}$ from $9.0 \times 10^{4}$ to $1.2 \times 10^{6}$ in toluene-supercritical carbon dioxide mixtures with different weight fractions of $\mathrm{CO}_{2}\left(\operatorname{denoted}\right.$ as $\left.w\left(\mathrm{CO}_{2}\right)\right)$ at $40{ }^{\circ} \mathrm{C}$ in a pressure range $P=7.0-10.0 \mathrm{MPa}$ using a rolling-ball viscometer. For every sample $[\eta]$ was a gradually increasing function of $P$, indicating that the polystyrene coil expands with increasing $P$. At fixed $P$ and $w\left(\mathrm{CO}_{2}\right)$, the molecular weight dependence of $[\eta]$ was expressed in the form $[\eta] \propto M_{\mathrm{w}}{ }^{a}$. The exponent $a$ remarkably changed with $w\left(\mathrm{CO}_{2}\right)$ at constant $P$; for example, it decreased from 0.68 (a good solvent value) to 0.42 (a poor solvent value below the theta point where $a=0.5$ ) with an increase in $w\left(\mathrm{CO}_{2}\right)$ from 15 to $31 \%$ at $P=7.0 \mathrm{MPa}$. The solvent goodness was quantified in terms of the binarycluster integral determined by analyzing the $[\eta]$ data according to the two-parameter theory.

KEY WORDS: Intrinsic Viscosity / High Pressure / Supercritical Liquid / Carbon Dioxide / Excluded-Volume Effect / Binary-Cluster Integral /

Supercritical carbon dioxide (critical temperature $31.1^{\circ} \mathrm{C}$ and pressure $7.38 \mathrm{MPa}$ ) is known to be compatible with many organic solvents. Such mixtures, in which polymer solubility is controllable by changing the pressure and the solvent composition, ${ }^{1-3}$ have possible applications to separation or blending of chemically different polymers and molecular weight fractionation of homopolymers. ${ }^{4,5}$ For the purpose of industrial processing, the dependence of viscosity $\eta$ on temperature, pressure, and solvent composition was investigated for polymer + organic solvent + supercritical $\mathrm{CO}_{2}$ systems. ${ }^{6,7}$ Most of these studies are, however, limited to rather high polymer concentrations (above $1 \mathrm{wt} \%$ ) and fixed molecular weights $M$, and none of them discusses the effect of polymer chain dimensions or related molecular properties on $\eta ; \eta$ of polymer solutions increases with increasing chain dimensions.

The intrinsic viscosity $[\eta]$ of a polymer coil (i.e., a long flexible chain) is a basic molecular property related closely to the chain dimensions. It increases with an increase in $M$ or solvent power (i.e., the strength of intramolecular excluded volume in a term of polymer statistical mechanics), but such dependence of $[\eta]$ in an organic solvent containing supercritical $\mathrm{CO}_{2}$ has not been explored despite the importance to our understanding of the effect of supercritical $\mathrm{CO}_{2}$ on polymer solution properties.

In the present work, we determine $[\eta]$ for polystyrene (PS) samples in toluene-supercritical $\mathrm{CO}_{2}$ mixtures as functions of molecular weight, solvent composition, and pressure higher than the boundary between one liquid phase and liquid-gas two phase regions. ${ }^{4}$ The relation between the extent of chain expansion and the solvent condition is discussed on the basis of excluded-volume theories. $^{8}$
Table I. Results from light scattering measurements on polystyrene samples in toluene at $15^{\circ} \mathrm{C}$

\begin{tabular}{lcccc}
\hline Sample & $M_{\mathrm{w}} \times 10^{-4}$ & $M_{\mathrm{w}} / M_{\mathrm{n}}{ }^{\mathrm{a}}$ & $\left\langle S^{2}\right\rangle^{1 / 2} / \mathrm{nm}$ & $\begin{array}{c}A_{2} \times 10^{4} \\
/ \mathrm{cm}^{3} \mathrm{~mol} \mathrm{~g}^{-2}\end{array}$ \\
\hline F-10 & 8.96 & 1.04 & 11.6 & 4.8 \\
F-20 & 18.6 & 1.04 & 16.8 & 4.5 \\
F-40 & 41.3 & 1.04 & 26.4 & 3.7 \\
F-80 & 66.1 & 1.05 & 34.5 & 3.2 \\
F-120 & 114 & 1.08 & 48.1 & 2.9 \\
F-128 & 119 & 1.05 & 50.1 & 2.8 \\
\hline
\end{tabular}

aManufacturer's values

\section{EXPERIMENTAL}

\section{Samples}

Tosoh's standard PS samples F-10, F-20, F-40, F-80, F-120, and F-128 were once solved in benzene and freeze-dried before use. Weight-average molecular weights $M_{\mathrm{w}}$ for these samples in toluene at $15^{\circ} \mathrm{C}$ were determined by light scattering on a Fica-50 light scattering photometer. The results are summarized in Table I, along with the z-average radii of gyration $\left\langle S^{2}\right\rangle^{1 / 2}$, second virial coefficients $A_{2}$, and weight to number-average molecular weight ratios $M_{\mathrm{w}} / M_{\mathrm{n}}$.

\section{Apparatus}

Rolling-ball viscometers are often used for viscosity measurements of liquids under high pressure..$^{9-13}$ Our apparatus including this type of viscometer is schematically shown in Figure 1. Liquid $\mathrm{CO}_{2}$ from the tank (a) is compressed by the pump (c) (JASCO Co. Ltd. PU-980), which has a jacket cooled by circulated water from the cooling bath (b). The pressure inside the rolling-ball viscometer (f) placed in a temperature

\footnotetext{
${ }^{1}$ Department of Macromolecular Science, Osaka University, 1-1 Machikaneyama-cho, Toyonaka 560-0043, Japan

${ }^{2}$ Department of Polymer Chemistry, Kyoto University, Katsura, Kyoto 615-8510, Japan

*To whom correspondence should be addressed (E-mail: yonaka@molsci.polym.kyoto-u.ac.jp).
} 


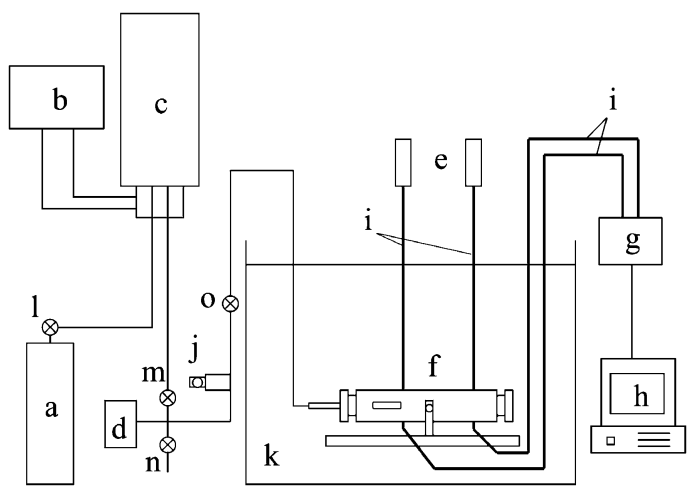

Figure 1. Schematic diagram of the apparatus constructed for viscosity measurements on polymer + organic solvent + supercritical $\mathrm{CO}_{2}$ systems. $a, \mathrm{CO}_{2}$ tank; b, water circulating bath; c, pump; d, pressure gauge; e, diode laser; $f$, rolling-ball viscometer; $g$, photo diode box; h, computer; i, optical fiber; j, safety valve; $k$, water bath; l-o, valves.

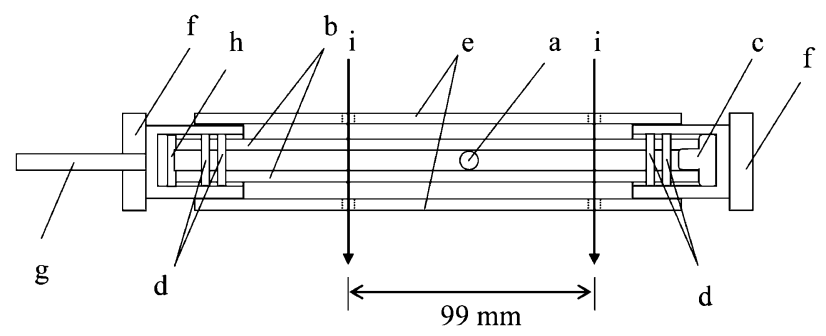

Figure 2. Schematic representation of rolling ball viscometer. a, glass ball; b, glass tube; c, Teflon stopper; d, gasket; e, stainless cylinder; $f$, stainless plug; g, $\mathrm{CO}_{2}$ inlet; h, Teflon ring; i, laser light path.

controlled water bath $(\mathrm{k})$ is monitored by the pressure gauge (d). Beams from the lasers (e) are incident to the viscometer through the optical fibers (i) and reach the photo diodes (g) after passing through the viscometer. The detected signal is processed by the computer (h).

\section{Viscosity Measurement}

The rolling-ball viscometer (i.e., the cylindrical cell) is magnified in Figure 2. A glass ball (diameter $5.8 \mathrm{~mm}$, TSC Co. Ltd., Kanagawa, Japan) is inserted in a Pyrex glass tube (inner diameter $6 \mathrm{~mm}$, outer diameter $16 \mathrm{~mm}$, and length $195 \mathrm{~mm}$, Taiatsu Glass Co. Ltd., Tokyo, Japan). The cylinder is inclined at about $7^{\circ}$ and the time required for the ball to move the distance between the two holes (separated by $99 \mathrm{~mm}$ in the middle of the cylindrical stainless jacket) is measured. The passage of the ball is optically detected at each hole where two glass fibers are inserted at the front and rear sides: one is for insertion of laser light and the other is for detection of the light by a photo diode at the other end of the fiber. The signals from the two photo diodes connected in series are processed by a computer to obtain the light intensity $V$ (arbitrary units).

Since $V$ abruptly decreases when the ball edge crosses the light path, two minimums appear for one hole as is shown in Figure 3. We take the time from the first to the third drop of $V$ as the rolling time $t$. The specific viscosity $\eta_{\mathrm{sp}}$ and the relative viscosity $\eta_{\mathrm{r}}$ were determined from $\left(t-t_{0}\right) / t_{0}$ and $t / t_{0}$,

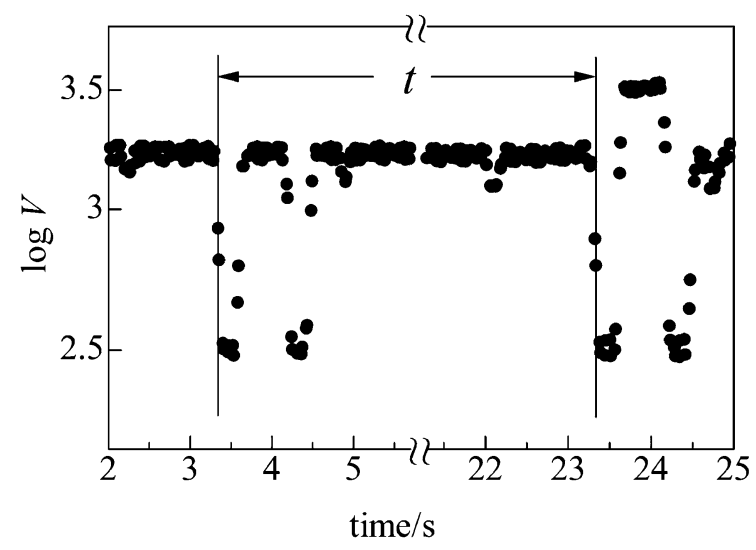

Figure 3. Example of photodiode signals.

respectively, where $t_{0}$ denotes the rolling time for the solvent at the same $P$ and temperature. The Huggins $\left(\eta_{\mathrm{sp}} / c\right.$ vs. $c$ ) and Fuoss-Mead $\left(\ln \eta_{\mathrm{r}} / c\right.$ vs. $\left.c\right)$ plots were used to extrapolate the measured viscosities to $c=0$ ( $c$ is the polymer mass concentration).

Before high pressure experiments, measurements were made on toluene solutions of a PS sample $\left(M \sim 2 \times 10^{5}\right)$ under atmospheric pressure. The $[\eta]$ value obtained agreed well with that determined by a conventional Ubbelohde-type capillary viscometer.

The procedure for the viscosity measurements on PS in toluene-supercritical $\mathrm{CO}_{2}$ mixtures was as follows. A toluene solution of PS with a known amount and concentration was introduced into the cylindrical cell. After the apparatus had been set up, the viscometer was placed in the water bath controlled at $40^{\circ} \mathrm{C}$. Carbon dioxide was then introduced through the stainless tube until the inside pressure $P$ reached a desired value $(7.0,8.5$, or $10.0 \mathrm{MPa})$. The solution was stirred by tilting the cylinder to obtain a homogenous phase. This is consistent with the observation of Kim et al. ${ }^{4}$ on the same system $\left(M_{\mathrm{w}}=6.66 \times 10^{5}, w\left(\mathrm{CO}_{2}\right)=15.0-16.6 \%\right)$ that the solution becomes one liquid phase above ca. $4.5 \mathrm{MPa}$ at $300 \mathrm{~K}$. After the attainment of the temperature and pressure equilibrium, measurements were made. The weight fraction $w\left(\mathrm{CO}_{2}\right)$ of $\mathrm{CO}_{2}$ was calculated from the measured solution weight and $P$ with the aid of the relation between the weight of $\mathrm{CO}_{2}$ and $P$ at $40{ }^{\circ} \mathrm{C}$ determined in advance for weighed pure toluene. The cylinder volume was found to be $7.4 \mathrm{~cm}^{3}$ from the known pressure-volume-temperature relation with the weight of pure $\mathrm{CO}_{2}$ contained at $10.0 \mathrm{MPa}$ and $25^{\circ} \mathrm{C}$. Figure 4 illustrates the Huggins and Fuoss-Mead plots for five PS samples at $w\left(\mathrm{CO}_{2}\right)=17 \%$ and $P=10.0 \mathrm{MPa}$. The common intercept at $c=0$ to the both plots gives $[\eta]$ for each sample.

\section{RESULTS AND DISCUSSION}

\section{Pressure Dependence}

Figure 5 shows $[\eta]$ data plotted against $P$ for five PS samples in toluene-supercritical $\mathrm{CO}_{2}$ mixtures with $w\left(\mathrm{CO}_{2}\right)=$ 15,16 , and $17 \mathrm{wt} \%$ (at $P=7.0,8.5$, and $10.0 \mathrm{MPa}$, respec- 

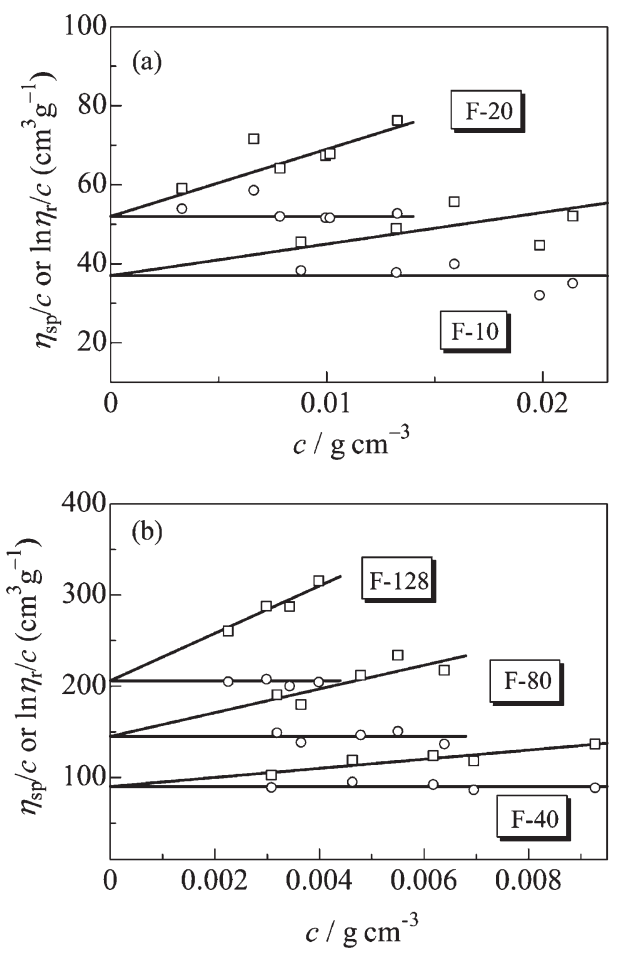

Figure 4. Huggins and Fuoss-Mead plots for the indicated PS samples at $w\left(\mathrm{CO}_{2}\right)=17 \%, P=10.0 \mathrm{MPa}$, and $40^{\circ} \mathrm{C}$.

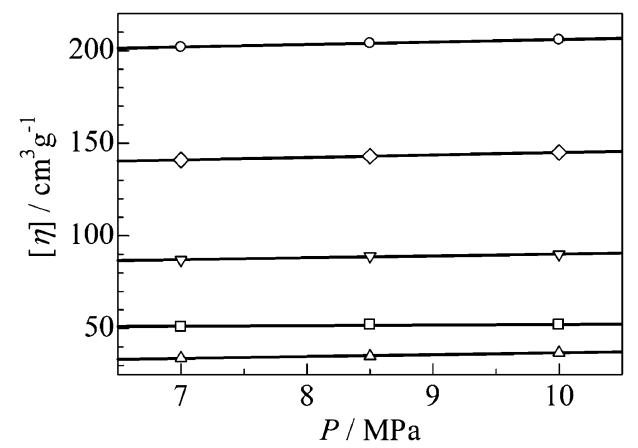

Figure 5. Plots of $[\eta]$ against $P$ for PS samples in toluene-supercritical $\mathrm{CO}_{2}$ with $w\left(\mathrm{CO}_{2}\right)=15(P=7.0 \mathrm{MPa}), 16(P=8.5 \mathrm{MPa})$, and $17 \mathrm{wt} \%$ $(P=10.0 \mathrm{MPa})$ at $40^{\circ} \mathrm{C}$ : triangles up, $\mathrm{F}-10$; squares, $\mathrm{F}-20$; triangles down, F-40; diamonds, F-80; circles, F-128.

tively). The line drawn for each sample rises very gradually with increasing $P$. Although this rise involves the effect of a small increase in $w\left(\mathrm{CO}_{2}\right)$, the increase in $\mathrm{CO}_{2}$ content lowers $[\eta]$ (see Figure 6). Thus, $[\eta]$ in toluene-supercritical $\mathrm{CO}_{2}$ mixtures is an increasing function of $P$. In other words, the solvent power (or goodness) increases with increasing $P$. Similar pressure dependence of $[\eta]$ was observed for such polymer + pure solvent systems as poly(dimethylsiloxane) in cyclohexyl bromide ${ }^{11}$ and PS in tert-butyl acetate. ${ }^{12}$ Positive pressure dependence of solvent goodness was also observed by light scattering measurements of $A_{2}$ for PS in toluene ${ }^{14,15}$ and PS in 2-butanone. ${ }^{16}$ On the other hand, for PS in trans-decalin, $[\eta]^{17}$ and $A_{2}{ }^{14,15}$ decreased with increasing $P$, exemplifying a lowering of solvent power with an increase in $P$.
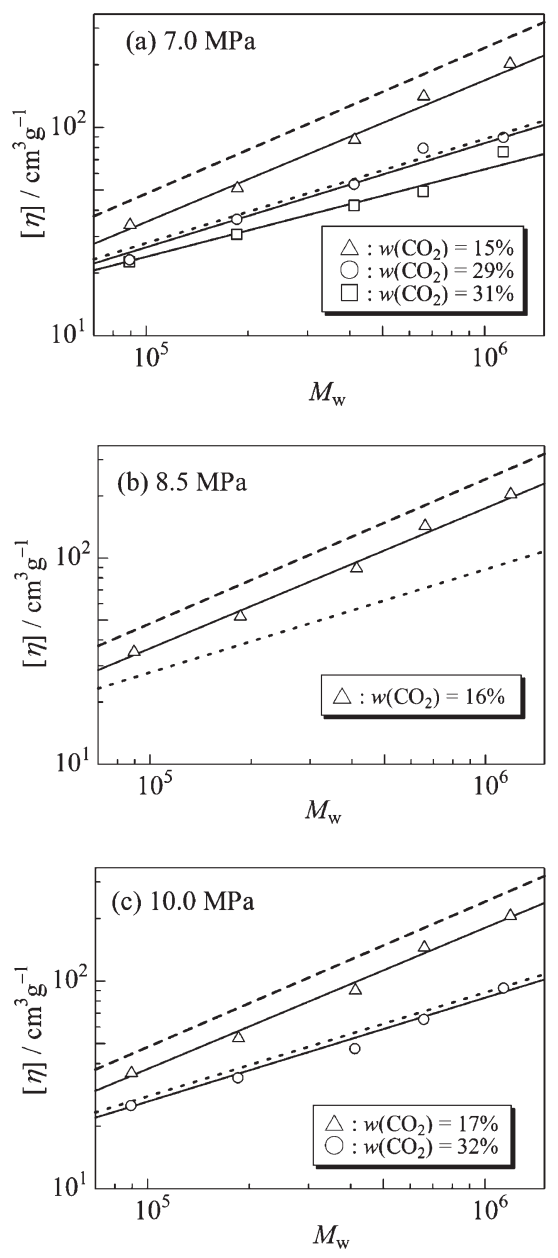

Figure 6. Molecular weight dependence of $[\eta]$ for PS in toluene-supercritical $\mathrm{CO}_{2}$ mixtures with the indicated compositions at (a) $P=7.0$, (b) 8.5 , and (c) $10.0 \mathrm{MPa}$, all at $40^{\circ} \mathrm{C}$. Solid lines represent eqs 1-6. Dashed and dotted lines show the literature data for PS in toluene at $15^{\circ} \mathrm{C}^{21}$ and in cyclohexane at $34.5^{\circ} \mathrm{C},{ }^{20}$ respectively.

It is known that the dielectric constant $\varepsilon$ of most organic solvents increases with increasing $P .{ }^{18}$ Such an increase in $\varepsilon$ of a solvent leads to either increase or decrease in solvent power depending on whether the difference in polarity between the solvent and the polymer diminishes or increases, as was observed for polymer + pure solvent systems. In our system, the increase in solvent power with increasing $P$ may be interpreted as the result of the enhancing effect of increasing $\varepsilon$ that surpasses the lowering effect of increasing $\mathrm{CO}_{2}$ in toluene. Li et al. ${ }^{19}$ found the opposite tendency, i.e., a decrease in $[\eta]$ with increasing $P$ for PS $\left(M_{\mathrm{w}}=7.8 \times 10^{4}\right)$ in toluene at $35^{\circ} \mathrm{C}$ under $\mathrm{CO}_{2}$ atmosphere of $P<4.2 \mathrm{MPa}$. In their system, in which the polymer solution and the $\mathrm{CO}_{2}$ gas phase coexist differing from our systems, $\varepsilon$ may not significantly change with $P$, because the pressure is not very high. As is mentioned in their paper, the decrease in $[\eta]$ can be attributed primarily to the increase in $\mathrm{CO}_{2}$ content in toluene with increasing $P$.

\section{Molecular Weight Dependence}

Figure 6 shows double-logarithmical plots of $[\eta]$ against $M_{\mathrm{w}}$ 
for PS in toluene-supercritical $\mathrm{CO}_{2}$ mixtures at different sets of $w\left(\mathrm{CO}_{2}\right)$ and $P$. The indicated straight lines fitting the data points for the respective sets can be expressed by the following equations (all in units of $\mathrm{cm}^{3} \mathrm{~g}^{-1}$ ):

At $P=7.0 \mathrm{MPa}$,

$$
\begin{array}{ll}
{[\eta]=0.014 M_{\mathrm{w}}{ }^{0.68}} & \text { for } w\left(\mathrm{CO}_{2}\right)=15 \% \\
{[\eta]=0.084 M_{\mathrm{w}}{ }^{0.50}} & \text { for } w\left(\mathrm{CO}_{2}\right)=29 \% \\
{[\eta]=0.19 M_{\mathrm{w}}{ }^{0.42}} & \text { for } w\left(\mathrm{CO}_{2}\right)=31 \%
\end{array}
$$

At $P=8.5 \mathrm{MPa}$,

$$
[\eta]=0.014_{5} M_{\mathrm{w}}{ }^{0.68} \text { for } w\left(\mathrm{CO}_{2}\right)=16 \%
$$

At $P=10.0 \mathrm{MPa}$,

$$
\begin{array}{ll}
{[\eta]=0.015 M_{\mathrm{w}}{ }^{0.68}} & \text { for } w\left(\mathrm{CO}_{2}\right)=17 \% \\
{[\eta]=0.083 M_{\mathrm{w}}{ }^{0.50}} & \text { for } w\left(\mathrm{CO}_{2}\right)=32 \%
\end{array}
$$

The viscosity exponent decreases with increasing $w\left(\mathrm{CO}_{2}\right)$, revealing that the solvent goodness remarkably lowers as the $\mathrm{CO}_{2}$ content increases.

The exponent 0.5 in eqs 2 and 6 corresponds to the theta state for random coils, i.e., for long flexible chains. The experimental data under the two solvent conditions (circles) are close to each other and also to the dotted line in Figure $6 a$ or $6 b$, which represents the literature $[\eta]$ data for PS in cyclohexane $\left(34.5^{\circ} \mathrm{C}\right),{ }^{20}$ a theta solvent. Lechner and $\mathrm{Schulz}^{14}$ showed that the unperturbed dimension of PS in toluene and trans-decalin decreases when the solution pressure increased up to $75 \mathrm{MPa}$. In our system, however, such hydrostatic pressure effect was not observed, probably because $P$ in our experiments is not as high as theirs.

Equations 1, 4, and 5 have a lager exponent 0.68, indicating that the polymer coil is expanded by excluded-volume effect. The solvent power is, however, lower than pure toluene because the $[\eta]$ data (triangles) are considerably below the dashed lines representing $[\eta]$ in toluene $\left(15^{\circ} \mathrm{C}\right) .{ }^{21}$ At $P=7.0 \mathrm{MPa}$ and $w\left(\mathrm{CO}_{2}\right)=31 \%$, the exponent 0.42 is much smaller than 0.5 (eq 3 ), implying that the solvent is very poor.

\section{Binary-Cluster Integral}

The binary-cluster integral $\beta$ representing the strength of the excluded-volume interaction between a pair of segments (or repeating units) in a single polymer chain is the most basic parameter for the solvent power and related to the excludedvolume parameter $z$ defined by ${ }^{8}$

$$
z=\left(3 / 2 \pi b^{2}\right)^{3 / 2} n^{1 / 2} \beta
$$

Here, $b$ is the segment length and $n$ the segment number in the polymer chain. With the intrinsic viscosity $[\eta]_{0}$ in the unperturbed state taken as the reference state, $[\eta]$ in a perturbed state can be written as ${ }^{8}$

$$
[\eta]=\alpha_{\eta}{ }^{3}[\eta]_{0}
$$

where the intrinsic-viscosity expansion factor $\alpha_{\eta}{ }^{3}$ may be given by Barrett's equation ${ }^{22}$
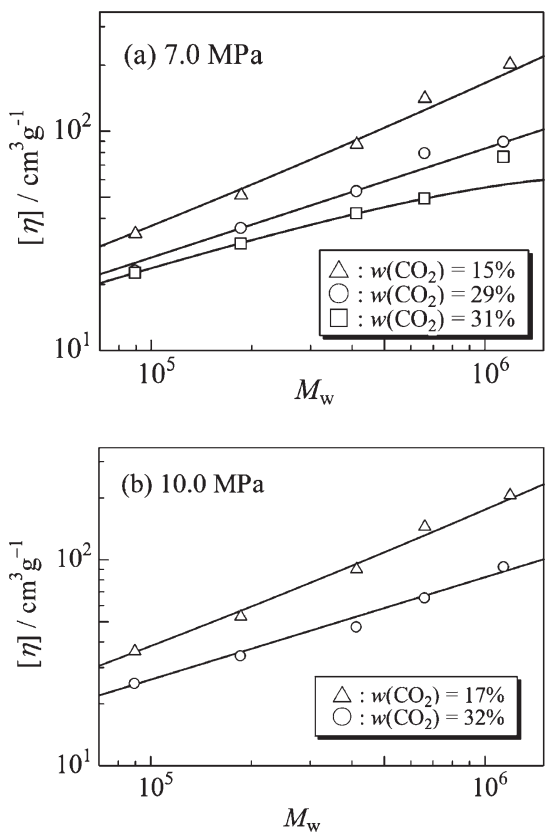

Figure 7. Comparison between observed (symbols) and calculated (solid lines) $[\eta]$ for PS samples in toluene-supercritical $\mathrm{CO}_{2}$ mixtures with the indicated compositions at (a) $P=7.0$ and (b) $10.0 \mathrm{MPa}$.

Table II. Binary-cluster integral for PS in toluene-supercritical $\mathrm{CO}_{2}$ mixtures with different $w\left(\mathrm{CO}_{2}\right)$ at $40^{\circ} \mathrm{C}$ and at the indicated pressures

\begin{tabular}{ccc}
\hline$P / \mathrm{MPa}$ & $w\left(\mathrm{CO}_{2}\right) / \%$ & $\beta / \mathrm{nm}^{3}$ \\
\hline \multirow{2}{*}{7.0} & 15 & 0.016 \\
& 29 & 0 \\
& 31 & -0.0034 \\
\hline \multirow{2}{*}{8.5} & 16 & 0.017 \\
\hline \multirow{2}{*}{10.0} & 17 & 0.019 \\
& 32 & 0 \\
\hline
\end{tabular}

$$
\alpha_{\eta}^{3}=\left(1+3.8 z+1.9 z^{2}\right)^{0.3}
$$

for $z>0$. For $z<0$ (i.e., at $P=7.0 \mathrm{MPa}$ and $w\left(\mathrm{CO}_{2}\right)=31 \%$ ), we may use the first-order perturbation equation ${ }^{8,23}$

$$
\alpha_{\eta}{ }^{3}=1+1.14 z
$$

Taking experimental $[\eta]$ for $w\left(\mathrm{CO}_{2}\right)=29 \%$ at $P=7.0 \mathrm{MPa}$ and $w\left(\mathrm{CO}_{2}\right)=32 \%$ at $P=10.0 \mathrm{MPa}$ as $[\eta]_{0}$, we may evaluate $[\eta]$ at these pressures and other $w\left(\mathrm{CO}_{2}\right)$ from the above equations. The calculated solid lines in Figure $7 \mathrm{a}$ and $7 \mathrm{~b}$ closely fit the data points for $P=7.0$ and $10.0 \mathrm{MPa}$, respectively.

The $\beta$ values determined from the fitting are summarized in Table II, where $b$ in eq 7 was taken to be $0.72 \mathrm{~nm}$ (from the radius of gyration of PS in cyclohexane at $34.5^{\circ} \mathrm{C}^{24}$ ). This table includes the $\beta$ value at $P=8.5 \mathrm{MPa}$ and $w\left(\mathrm{CO}_{2}\right)=16 \%$, similarly estimated with use of eq 2 for $[\eta]_{0}$. At almost the same $\mathrm{CO}_{2}$ contents between 15 and $17 \%, \beta$ increases with raising $P$, reflecting the increase in solvent goodness. 


\section{CONCLUSIONS}

We have determined intrinsic viscosities for five polystyrene samples of molecular weights $9.0 \times 10^{4}-1.2 \times 10^{6}$ in toluenesupercritical $\mathrm{CO}_{2}$ mixutures at $40^{\circ} \mathrm{C}$ under high pressure (7$10 \mathrm{MPa}$ ). The results show that the increase in $\mathrm{CO}_{2}$ content remarkably changes the solubility of polystyrene as indicated by a decrease in viscosity exponent $a$, for example, from 0.68 to 0.42 at $P=7.0 \mathrm{MPa}$. In case of $P=7.0 \mathrm{MPa}$ and $w\left(\mathrm{CO}_{2}\right)=29 \%$ or $P=10.0 \mathrm{MPa}$ and $w\left(\mathrm{CO}_{2}\right)=32 \%, a$ becomes equal to the value 0.5 for the theta solvent system. Estimation of the binary-cluster integral from $[\eta]$ data based on the two-parameter theory substantiates that the solvent goodness in the present system is an increasing function of $P$.

Received: December 12, 2008 Accepted: February 13, 2009

Published: April 1, 2009

\section{REFERENCES}

1. M. A. McHugh and T. L. Guckes, Macromolecules, 18, 674 (1985).

2. A. A. Kiamos and M. D. Donohue, Macromolecules, 27, 357 (1994).

3. S. N. Joung, J.-U. Park, S. Y. Kim, and K.-P. Yoo, J. Chem. Eng. Data, 47, 270 (2002).
4. S. Kim, Y.-S. Kim, and S.-B. Lee, J. Supercrit. Fluids, 13, 99 (1998).

5. K. Liu and E. Kiran, Polymer, 49, 1555 (2008).

6. S.-D. Yeo and E. Kiran, Macromolecules, 32, 7325 (1999).

7. S.-D. Yeo and E. Kiran, J. Appl. Polym. Sci., 75, 306 (2000).

8. H. Yamakawa, "Modern Theory of Polymer Solutions," Harper \& Row, New York, 1971.

9. R. M. Hubbard and G. G. Brown, Ind. Eng. Chem., Anal. Ed., 15, 212 (1943).

10. L. T. Carmichael and B. H. Sage, Ind. Eng. Chem., 44, 2728 (1952).

11. K. Kubota and K. Ogino, Macromolecules, 12, 74 (1979).

12. J. R. Schmidt and B. A. Wolf, Macromolecules, 15, 1192 (1982).

13. S. Sawamura, N. Takeuchi, K. Kitamura, and Y. Taniguchi, Rev. Sci. Instrum., 61, 871 (1990).

14. M. Lechner and G. V. Schulz, Eur. Polym. J., 6, 945 (1970).

15. G. V. Schulz and M. Lechner, J. Polym. Sci., Part A-2, 8, 1885 (1970).

16. D. Gaeckle and D. Patterson, Macromolecules, 5, 136 (1972).

17. K. Kubota and K. Ogino, Polymer, 20, 175 (1979).

18. J. F. Skinner, E. L. Cussler, and R. M. Fuoss, J. Phys. Chem., 72, 1057 (1968).

19. D. Li, B. Han, Z. Liu, J. Liu, X. Zhang, S. Wang, X. Zhang, J. Wang, and B. Dong, Macromolecules, 34, 2195 (2001).

20. Y. Einaga, Y. Miyaki, and H. Fujita, J. Polym. Sci., Polym. Phys. Ed., 17, 2103 (1979).

21. F. Abe, Y. Einaga, and H. Yamakawa, Macromolecules, 26, 1891 (1993).

22. A. J. Barrett, Macromolecules, 17, 1566 (1984).

23. J. Shimada and H. Yamakawa, J. Polym. Sci., Polym. Phys. Ed., 16, 1927 (1978).

24. Y. Miyaki, Y. Einaga, and H. Fujita, Macromolecules, 11, 1180 (1978). 